9. Lins RM, Oliveira SG, Souza NA, de Queiroz RG, Justiniano SC, Ward RD, et al. Molecular evolution of the cacophony IVS6 region in sandflies. Insect Mol Biol. 2002;11:117-22. http://dx.doi.org/10.1046/j.1365-2583.2002.00315.x

Addresses for correspondence: Carlos Robello, Unidad de Biología, Molecular Institut Pasteur de Montevideo, Mataojo 2020 CP11400, Montevideo, Uruguay; email: robello@pasteur.edu.uy; Yester Basmadjián, Departamento de Parasitología y Micología, Instituto de Higiene. Avda Alfredo Navarro 3051, CP 11600, Montevideo, Uruguay; email: yesterb@gmail.com

\section{Worldwide Endemicity of a Multidrug-Resistant Staphylococcus capitis Clone Involved in Neonatal Sepsis}

\author{
Marine Butin, Patricia Martins-Simões, \\ Jean-Philippe Rasigade, Jean-Charles Picaud, \\ Frédéric Laurent
}

\begin{abstract}
Author affiliations: Hospices Civils de Lyon, Lyon, France (M. Butin, P. Martins-Simões, J-P. Rasigade, J-C. Picaud, F. Laurent); INSERM, Lyon (M. Butin, P. Martins-Simões, J-P. Rasigade, F. Laurent); Claude Bernard University Lyon 1, Villeurbanne, France (J-P. Rasigade, J-C. Picaud, F. Laurent)

DOI: http://dx.doi.org/10.3201/eid2303.160833

A multidrug-resistant Staphylococcus capitis clone, NRCS$A$, has been isolated from neonatal intensive care units in 17 countries throughout the world. S. capitis NRCS-A prevalence is high in some neonatal intensive care units in France. These data highlight the worldwide endemicity and epidemiologic relevance of this multidrug-resistant, coagulase-negative staphylococci clone.
\end{abstract}

$\mathrm{P}$ reterm birth is the world's leading cause of death before 5 years of age (1). Neonatal sepsis, mostly due to coagulasenegative staphylococci, occurs frequently in neonatal intensive care units, especially in very low birthweight preterm infants (2). Cases and series of neonatal sepsis involving Staphylococcus capitis have been reported in different countries (3) and were initially considered unrelated epidemic bursts. More recently, we detected a single multidrug-resistant clone of $S$. capitis, designated as the NRCS-A clone and characterized by a specific pulsed-field gel electrophoresis (PFGE) pattern, in several neonatal intensive care units (NICUs) in France, Belgium, the United Kingdom, and Australia $(4,5)$. The clonality of the strains was confirmed by PFGE, multilocus sequence typing-like analysis, and whole-genome sequencing. We also showed that all NRCS-A isolates exhibited a decreased susceptibility to all of the antimicrobial agents frequently used in NICUs, namely $\beta$-lactams, aminoglycosides, and vancomycin (5). Furthermore, a recent study showed that $S$. capitis NRCSA-associated sepsis constitutes an independent risk factor for severe illness in neonates $(6)$.

We suspected that the initial report of NRCS-A dissemination in NICUs from 4 distant countries was only the tip of the iceberg and that the spread of NRCS-A strains was much wider than expected. To determine the extent of NRCS-A dissemination, we asked microbiologic laboratories worldwide to send us methicillin-resistant $S$. capitis strains isolated from blood cultures of neonates. These isolates were identified by matrix-assisted laser desorption/ionization time-of-flight mass spectrometry and subjected to PFGE using the SmaI restriction enzyme as previously described (7). NRCS-A's characteristic PFGE pattern was found for 154 strains isolated between 1994 and 2015 in 34 NICUs from 17 countries: Australia, Belgium, Brazil, Canada, Czech Republic, Denmark, Finland, France, Germany, the Netherlands, New Zealand, Norway, South Korea, Switzerland, Taiwan, the United Kingdom, and the United States.

Retrospective, laboratory-based epidemiologic investigations to estimate the prevalence of NRCS-A strains in NICUs could not be performed on the same worldwide scale, so we conducted such a study in France. Results collected from 47 of the 57 NICUs in France during 2014 indicated that only 4 NICUs were free of NRCS-A. In the 43 other NICUs, NRCS-A strains accounted for up to $46 \%$ of all cases of positive cultures of blood from neonates (median 13\%, interquartile range $10 \%-20 \%$ ) and represented $19 \%$ of all coagulase-negative staphylococci strains isolated from the blood cultures of neonates.

Taken together, these data unquestionably demonstrate the unusual worldwide endemicity of the multidrug-resistant NRCS-A clone in NICUs. In addition, the epidemiologic data from France highlight the propensity of NRCS-A to invade and settle in most NICUs on a national scale. Once endemic in a NICU, NRCS-A strains expose infected neonates to a risk of therapeutic failure because treatment of neonatal sepsis involving methicillin-resistant coagulase-negative staphylococci is usually based on vancomycin and aminoglycosides, to which NRCS-A isolates are not susceptible (3-5).

A thorough investigation of the determinants of the worldwide spread of NRCS-A is urgently needed to unravel the dissemination routes and reservoirs of this multidrugresistant clone and to succeed in managing and controlling its diffusion. The risk of vancomycin treatment failure warrants an investigation of alternate antimicrobial stewardship strategies, in particular linezolid, daptomycin, and ceftarolin, to treat NRCS-A-associated neonatal sepsis. 


\section{Acknowledgments}

We gratefully acknowledge V. Adamkova, A. Becker, M. Deighton, O. Denis, J. Ferguson, A. Friedrich, Y.C. Huang, A. Ingebretsen, A. Kearns, K. Klingenberg, C. Laferrière, B. Pichon, K. Regina Netto dos Santos, J. Schrenzel, K. TaekSoo, E. Tarkka, J. Ussher, C. Vandenbroucke-Graulsfor, and $\mathrm{L}$. Westblade for the timely selection and sending of S. capitis isolates, as well as Louise Hoden and the team at the French National Reference Center for Staphylococci for their expert technical assistance.

Dr. Butin is a pediatrician working in the neonatal intensive care unit of the Hôpital Femme Mère Enfant, Hospices Civils de Lyon, Lyon, France. Her primary research interests are the epidemiology, pathophysiology, and clinical determinants of infections in neonates, notably Staphylococcusassociated infections.

\section{References}

1. Liu L, Oza S, Hogan D, Perin J, Rudan I, Lawn JE, et al. Global, regional, and national causes of child mortality in 2000-13, with projections to inform post-2015 priorities: an updated systematic analysis. Lancet. 2015;385:430-40. http://dx.doi.org/10.1016/ S0140-6736(14)61698-6

2. Boghossian NS, Page GP, Bell EF, Stoll BJ, Murray JC, Cotten CM, et al.; Eunice Kennedy Shriver National Institute of Child Health and Human Development Neonatal Research Network. Late-onset sepsis in very low birth weight infants from singleton and multiple-gestation births. J Pediatr. 2013;162:1120-4, 1124.e1. http://dx.doi.org/10.1016/j. jpeds.2012.11.089

3. Van Der Zwet WC, Debets-Ossenkopp YJ, Reinders E, Kapi M, Savelkoul PH, Van Elburg RM, et al. Nosocomial spread of a Staphylococcus capitis strain with heteroresistance to vancomycin in a neonatal intensive care unit. J Clin Microbiol. 2002;40:2520-5. http://dx.doi.org/10.1128/JCM.40.7.2520-2525.2002

4. Rasigade J-P, Raulin O, Picaud J-C, Tellini C, Bes M, Grando J, et al. Methicillin-resistant Staphylococcus capitis with reduced vancomycin susceptibility causes late-onset sepsis in intensive care neonates. PLoS One. 2012;7:e31548. http://dx.doi.org/10.1371/ journal.pone. 0031548

5. Butin M, Rasigade J-P, Martins-Simões P, Meugnier H, Lemriss H, Goering RV, et al. Wide geographical dissemination of the multiresistant Staphylococcus capitis NRCS-A clone in neonatal intensive-care units. Clin Microbiol Infect. 2016;22: 46-52. http://dx.doi.org/10.1016/j.cmi.2015.09.008

6. Ben Said M, Hays S, Bonfils M, Jourdes E, Rasigade JP, Laurent F, et al. Late-onset sepsis due to Staphylococcus capitis 'neonatalis' in low-birthweight infants: a new entity? J Hosp Infect. 2016;94:95-8. http://dx.doi.org/10.1016/j.jhin.2016.06.008

7. Goering RV. Molecular epidemiology of nosocomial infection: analysis of chromosomal restriction fragment patterns by pulsed-field gel electrophoresis. Infect Control Hosp Epidemiol. 1993;14:595-600. http://dx.doi.org/10.2307/30105130

Address for correspondence: Marine Butin, Department of Neonatal Intensive Care, Eastern Hospital Group Hospices Civils de Lyon, 59 Bd Pinel, 69500 Lyon Bron, France; email: marine.butin@chu-lyon.fr

\section{Potentially Zoonotic Bartonella in Bats from France and Spain}

\author{
Matthew J. Stuckey, Henri-Jean Boulouis, \\ Florence Cliquet, Evelyne Picard-Meyer, \\ Alexandre Servat, Nidia Aréchiga-Ceballos, \\ Juan E. Echevarría, Bruno B. Chomel
}

Author affiliations University of California, Davis, USA

(M.J. Stuckey, B.B. Chomel); Ecole Nationale Vétérinaire d'Alfort, Maisons-Alfort, France (H.-J. Boulouis); Agence Nationale de Sécurité Sanitaire de l'Alimentation, de l'Environnement et du Travail (ANSES), Laboratoire de la Rage et de la Faune Sauvage de Nancy, Malzéville, France (F. Cliquet, E. Picard-Meyer, A. Servat); Laboratorio de Rabia, Instituto de Diagnóstico y Referencia Epidemiológicos, Mexico City, Mexico (N. AréchigaCeballos); Centro de Investigación Biomédica en Red de Epidemiología y Salud Pública (CIBERESP), Instituto de Salud Carlos III, Madrid, Spain (J.E. Echevarría)

DOI: http://dx.doi.org/10.3201/eid2303.160934

We detected Bartonella in 11 of 109 insectivorous bats from France and 1 of 26 bats from Spain. These genetic variants are closely related to bat-associated Bartonella described in Finland and the United Kingdom and to B. mayotimonensis, the agent of a human endocarditis case in the United States.

$\mathrm{B}$ artonellae have been identified in bats sampled in locations around the world where diverse chiropteran host species can interact with numerous Bartonella variants and potential arthropod vectors (1-3). Many Bartonella species are zoonotic, potentially affecting human and bat health (4). Bartonella spp. in bat populations of Europe are of particular interest because some variants described in Finland and the United Kingdom are closely related to Bartonella mayotimonensis, a species detected in the resected aortic valve of a 59-year-old endocarditis patient in the United States $(5,6)$. To determine if potentially zoonotic bat-associated bartonellae are circulating elsewhere in Europe, we tested insectivorous bats from France and Spain for the presence of Bartonella spp.

We performed necropsies on 26 bats from Spain and 109 from France to collect heart tissue for Bartonella spp. diagnostics (online Technical Appendix Table 1, https://wwwnc. cdc.gov/EID/article/23/3/16-0934-Techapp1.pdf). Bats from Spain were originally collected during active surveillance for rabies at the Unidad de Aislamiento y Detección Virus, Instituto de Salud Carlos III, Madrid, Spain. Of the bats from France, 97 were originally submitted for passive rabies surveillance to the Agence Nationale de Sécurité Sanitaire 